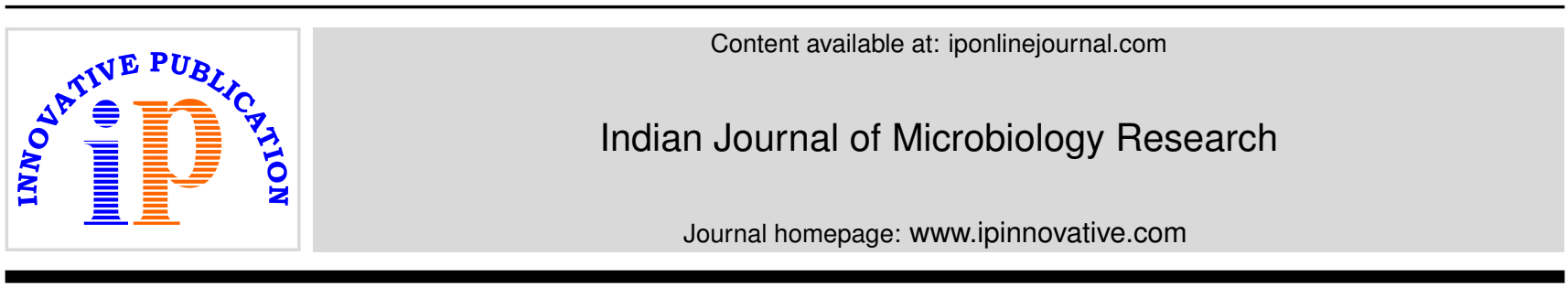

Original Research Article

\title{
A study on the distribution and hydrolytic enzyme potential of yeasts in the mangrove sediments of Northern Kerala
}

\author{
Vidya Pothayi ${ }^{1}$, Sebastian Chempakassery Devasia ${ }^{1, *}$ \\ ${ }^{1}$ Dept. of Zoology, University of Calicut, Calicut, Kerala, India
}

\section{A R T I C L E I N F O}

\section{Article history:}

Received 23-03-2020

Accepted 23-04-2020

Available online 20-07-2020

\section{Keywords:}

\section{Bioactivity}

Conservation

Industrial Processes

Mangroves

Organic matter

Yeast

\begin{abstract}
A B S T R A C T
Mangrove sediments, due to their unique environment, are considered to be a crucial habitat in identifying yeast strains with potent industrial, biotechnological and bioremediation properties. The present study investigates the distribution and hydrolytic enzyme potential of yeast isolates from North Kerala with respect to changes in seasonal and sediment characteristics. Sediment samples were collected from 8 locations spreading in 5 districts along the northern coast of Kerala during monsoon and post monsoon seasons of a year. The $\mathrm{pH}$ of the sediments varied between 6.4 to 7.0 , temperature between $21^{\circ} \mathrm{C}-29^{\circ} \mathrm{C}$ and organic matter content between $1.7 \% \pm \mathrm{SD}-4.2 \% \pm \mathrm{SD}$. The number of Colony Forming Units per milliliter of the sample (CFU/ml) of the cultivable yeasts varied drastically between the seasons. A total of 233 isolates were studied during the specified period of study, out of which $82 \%$ of the isolates showed various hydrolytic enzyme activities during monsoon while $89 \%$ in post monsoon. Lipase and Ligninase activity was shown by maximum number of isolates. It was found from this study that as the moisture content and organic matter of the sediment decreased, the CFU/ml of cultivable yeasts decreased considerably while the number of potent isolates with hydrolytic enzyme activity increased. The extracellular enzymes produced by yeasts possess variety of applications in industrial processes and are also very important in the environment due to their capacity of biodegradation. Hence, the present work attempts to understand the ecological and seasonal influence on the distribution and the bioactivity of cultivable yeast strains from a unique yet least studied environment like mangroves.
\end{abstract}

(C) 2020 Published by Innovative Publication. This is an open access article under the CC BY-NC license

(https://creativecommons.org/licenses/by-nc/4.0/)

\section{Introduction}

Mangroves are one of the unique ecosystems on earth with high productivity and complex environment. They possess close interaction between plants, animals and microorganisms and exhibit high rate of organic matter and nutrient cycling. The sediments of mangroves are rich in microorganisms, which in turn play an integral part in productivity, biogeochemical cycles and in environment recovery. ${ }^{1}$ The composition and assemblage of microbes in mangrove sediments are effected by various factors like nutrient availability, biogeochemical cycles, depth, tidal influence and anthropogenic disturbances. ${ }^{2}$ Lately, mangroves around the world are found to be at risk of

\footnotetext{
* Corresponding author.

E-mail address: drcdsebastian@gmail.com (S. C. Devasia).
}

destruction due to factors like pollution, deforestation and other human interactions which demands management and conservation of this ecosystem. A detailed investigation on the composition and distribution of microbial communities and the factors affecting them would help us in understanding the ecosystem dynamics better.

The sediments of mangroves are detritus based and this makes them the hotspots of yeast diversity. They serve as unique habitat for studying yeast composition and identifying strains with potent industrial, biotechnological and bioremediation properties. Mangrove yeasts which are similar to marine yeasts in nature have wide ecological significance. They are actively involved in nutrient recycling, decomposition of litter and degradation of oil and recalcitrant substances. ${ }^{3}$ The hydrolytic enzymes present in yeasts are found to be involved in transformation activities 
and this can be used in various industrial applications. ${ }^{4}$ The population of yeast in sediments is studied to be dependent majorly on the type and concentration of organic matter present. Existing environmental conditions also found to have significant effect on the number, distribution and metabolic properties of yeast present in a particular ecosystem. ${ }^{5}$

Although, a large number of studies about terrestrial and aquatic yeasts are available, ${ }^{6-8}$ there are only few reports about marine and estuarine yeasts especially mangrove yeasts $^{9-12}$ despite their importance. India has the fourth largest mangrove area in the world which contributes to the $7 \%$ of the world mangroves. ${ }^{13}$ The vast species diversity in mangroves and the occurrence of discrete seasonal and environmental variations in the Indian sub continent makes it an ideal study ground to understand the composition and metabolic characteristics of sediment microbes, especially yeasts. Kerala, which belongs to the west coast of India, has wide areas of luscious and uninterrupted mangrove ecosystems and the climate of the state is majorly influenced by the monsoon. Hence, the yeasts community present in the mangrove sediments of this area is thought to have discrete distribution and metabolic properties. Despite this, there is a lack of information regarding yeasts from mangroves of India and their bioactivity; specifically those from mangroves of Kerala. Against this back drop, the present study attempts to investigate the distribution and hydrolytic enzyme potential of yeast isolates from mangroves of Northern Kerala during particular seasons of the year.

\section{Materials and Methods}

Sediment samples were collected from the mangroves of the 5 districts along North Kerala coast in 8 sites, namely Chandragiri (KGD), $12^{\circ} 05^{\prime} 32^{\prime \prime} \mathrm{N} 75^{\circ} 13^{\prime} 39^{\prime \prime} \mathrm{E}$ (Kasaragod Dt), Edat (EDT), $12^{\circ} 05^{\prime} 32^{\prime \prime} \mathrm{N} 75^{\circ} 13^{\prime} 39^{\prime \prime}$ E; Pazhayangadi (PYD), $12^{\circ} 02^{\prime}$ 72” $\mathrm{N} 75^{\circ} 29^{\prime} 31^{\prime \prime}$ E; Valapattanam (VPT), 11 $93^{\circ} 45^{\prime \prime} \mathrm{N} 75^{\circ} 35^{\prime} 35^{\prime \prime}$ 'E (Kannur

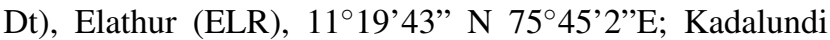
(KDI), $11^{\circ} 07^{\prime} 43^{\prime \prime} \mathrm{N} 75^{\circ} 49^{\prime} 48^{\prime \prime} \mathrm{E}$ (Kozhikode Dt), Ponnani (PON), 10 47'1'N 75'55'3”'E (Malappuram Dt) and Chettuva (CTV), $11^{\circ} 1{ }^{\prime} 41^{\prime \prime} \mathrm{N} 75^{\circ} 52^{\prime} 6^{\prime \prime} \mathrm{E}$ (Thrissur Dt) (Figure 1). Samples were collected from the same spots of the collection site during two periods of the year viz., monsoon (June 2018 - September 2018) and post monsoon (December 2018 - March 2019). Approximately 10-20g of sediment from the sub surface $(0-15 \mathrm{~cm})$ was collected using hand core method and was transferred aseptically into sterile polythene bags. The collected samples were transported in ice boxes and processed within $4 \mathrm{hrs}$ of collection. A total of five sub-samples were collected from each location and these samples were later homogenized, resulting in one composite sample.

For the isolation of yeasts, plating of the sediment samples were done employing spread plate method in
Wickerham's agar supplemented with $200 \mathrm{mg} / \mathrm{l}$ chloramphenicol ${ }^{14}$ in duplicates. The plates were incubated at $18 \pm 2^{\circ} \mathrm{C}$ for 7 days and the colonies developed were purified by quadrant streaking and transferred to malt extract agar slants for further studies. Isolates were stocked in malt extract agar vials overlaid with sterile liquid paraffin for long term storage.

Physico chemical characteristics of the sediments like $\mathrm{pH}$, temperature and salinity were measured during the time of collection using portable digital $\mathrm{pH}$ meter, mercury thermometer and digital salinometer respectively. The percentage organic matter and sediment texture of the air dried sediment samples were analysed in triplicates using modified Walkley and Black method. ${ }^{15}$

All the isolates obtained during the study periods were tested for the production of enzymes viz., protease, amylase, lipase, urease, ligninase, cellulase, DNase, pectinase and chitinase. Nutrient agar medium supplemented with casein (2\%), starch (1\%), tributyrin (1\%) and colloidal chitin $(5 \%)$, were used for the detection of protease, amylase, lipase and chitinase respectively. DNase agar, Cellulose agar, Pectin agar, Urease agar with $40 \%$ urea and Crawford's agar supplemented with $0.5 \%$ tannic acid were used for the detection of DNase, cellulase, pectinase, urease and ligninase activity respectively. The plates were spot inoculated and incubated at room temperature $\left(28 \pm 2^{\circ} \mathrm{C}\right)$ for 7 days. Formation of clearance/halo zone or brown colour around the colonies was considered as positive. Marine oxidation fermentation (MOF) medium was used for testing the ability of the yeast isolates to utilize dextrose aerobically (oxidative) or anaerobically (fermentative).

\section{Results}

A total of 233 yeast isolates were obtained, studied and stored during the collection period in which 129 isolates were obtained during monsoon and 104 isolates during post monsoon. The number of colony forming units per milli litre $(\mathrm{CFU} / \mathrm{ml})$ of the diluted sediment sample from each of the duplicate plates was calculated and the average number was taken in to consideration. The $\mathrm{CFU} / \mathrm{ml}$ of yeast in mangrove sediments showed significant difference between the sampling periods (Figure 2). During monsoon, maximum $\mathrm{CFU} / \mathrm{ml}$ was found in the mangrove sediments from Chettuva (1700) while those from Payangadi showed the minimum CFU/ml (66). This trend was different during post monsoon period where the sediments from Ponnani showed maximum CFU/ml (250) while those of Elathur showed minimum value (10).

The physico chemical parameters of the sediments like $\mathrm{pH}$ and temperature of the mangrove sediments were recorded from sampling sites during the time of collection. The Organic matter content and the sediment texture were analyzed later in the laboratory. $\mathrm{pH}$ of the sediments varied between $6.4-7$ (Figure 3), temperature of the sediments 


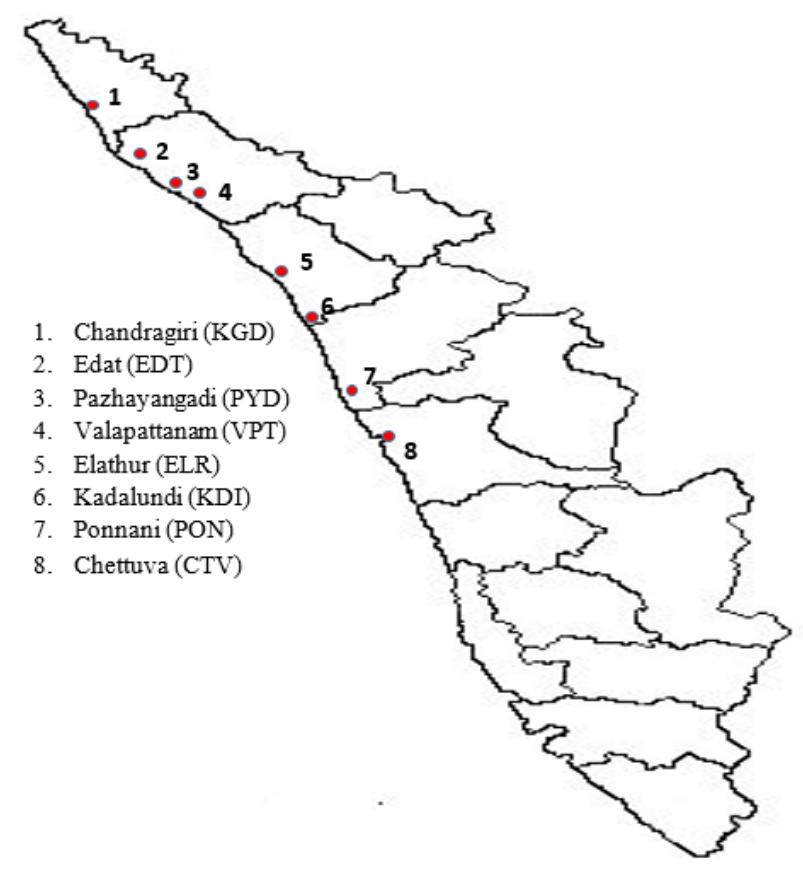

Fig. 1: Map of Kerala showing the sites of collection of mangrove sediments. Scale bar $1 \mathrm{~mm}=1 \mathrm{Km}$

varied between $21^{\circ} \mathrm{C}-29^{\circ} \mathrm{C}$ (Figure 4) and Organic matter content of the sediment varied between $1.7 \% \pm \mathrm{SD}-4.2 \%$ \pm SD (Figure 5) during the period of study. The organic matter in the sediments of the study sites was found to be higher during monsoon and lower during post monsoon period. The sediment texture analysis showed that $70 \%$ of its composition consisted of sand compared to clay and silt.

The hydrolytic enzyme activity of the yeast isolates obtained during the study period showed considerable variations between the monsoon and post monsoon periods. The number of isolates showing enzymatic potential (referred in this paper as positive forms) in each season is calculated and is expressed as percentage. The results showed that the number of yeast isolates having hydrolytic activity increased during post monsoon compared to monsoon. $82 \%$ of the isolates showed various hydrolytic enzyme activities during monsoon while $89 \%$ of them in post monsoon. Maximum number of isolates having enzyme activity was obtained from the mangrove sediments of Chettuva and Kasargod and those with minimum activity were from Kadalundi during the entire study period. Significant changes were found in the pattern of enzymatic activity showed by the yeast isolates between two seasons. The order of the enzyme activity showed by the yeast isolates (positive forms) during monsoon was found to be Lipase $>$ Ligninase $>$ Urease $>$ Amylase $>$ Cellulase $>$ DNase $>$ Protease $>$ Chitinase $>$ Pectinase and that of post monsoon was Lipase $>$ Ligninase $>$ Pectinase $>$ Urease $>$ Cellulase $>$ Protease $>$ DNase $>$ Amylase $>$
Chitinase (Figures 6 and 7). Lipase and Ligninase enzyme activity were shown by maximum number of isolates while Chitinase and pectinase activity by minimum number of isolates obtained during the study period. There was no pectinolytic isolates during monsoon while $20 \%$ of the isolates showed pectinolytic activity in post monsoon.

Microscopic appearance of the vegetative cells of the isolates showed budding and hyphal formation. Asexual reproductive forms which were budding in nature mostly belonging to Candida dominated highly over sexual forms which reproduced by spore formation. During monsoon period, fermentative forms $(57 \%)$ dominated over oxidative forms (43\%), but post monsoon, oxidative forms (62\%) dominated over fermentative forms (38\%) (Figure 8 ).

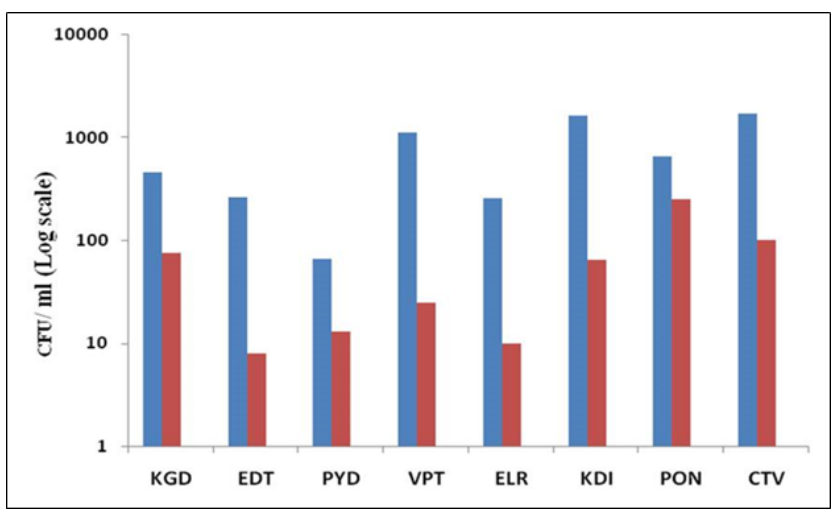

Fig. 2: $\mathrm{CFU} / \mathrm{ml}$ of cultivable yeast colonies from the collection sites during monsoon (blue bars) and post monsoon (red bars)

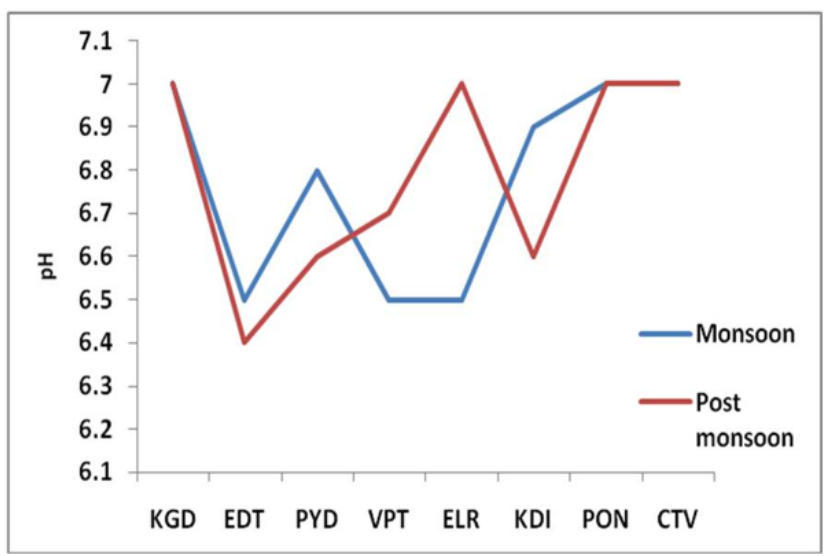

Fig. 3: $\mathrm{pH}$ of the sediments from the collection sites during monsoon and post monsoon KGD- Kasaragod, EDT - Edat, PYD - Pazhayangadi, VPT - Valapattanam, ELR - Elathur,KDI - Kadalundi, PON - Ponnani, CTV - Chettuva

\section{Discussion}

The present study showed a drastic decrease in the CFU/ $\mathrm{ml}$ of cultivable yeast colonies from the sediments of 


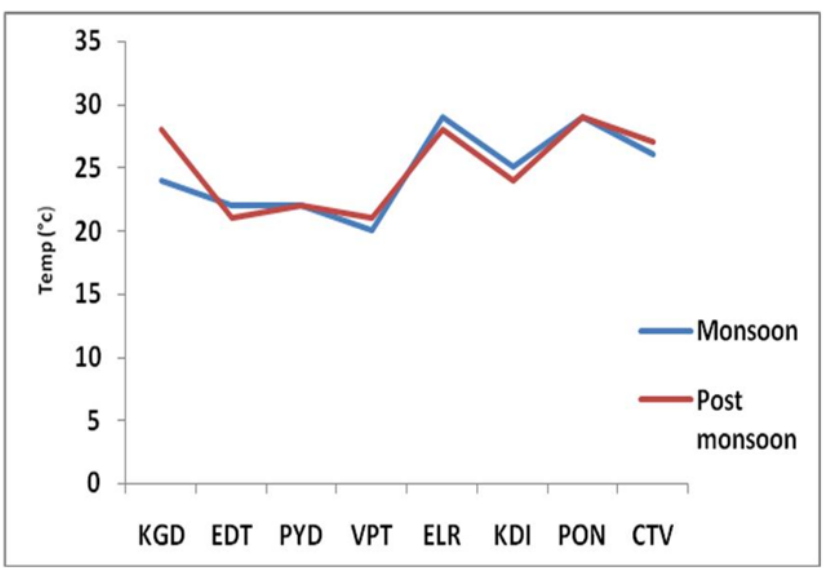

Fig. 4: Temperature of the sediments from the collection sites during monsoon and post monsoon KGD- Kasaragod, EDT - Edat, PYD - Pazhayangadi, VPT - Valapattanam, ELR Elathur,KDI - Kadalundi, PON - Ponnani, CTV - Chettuva

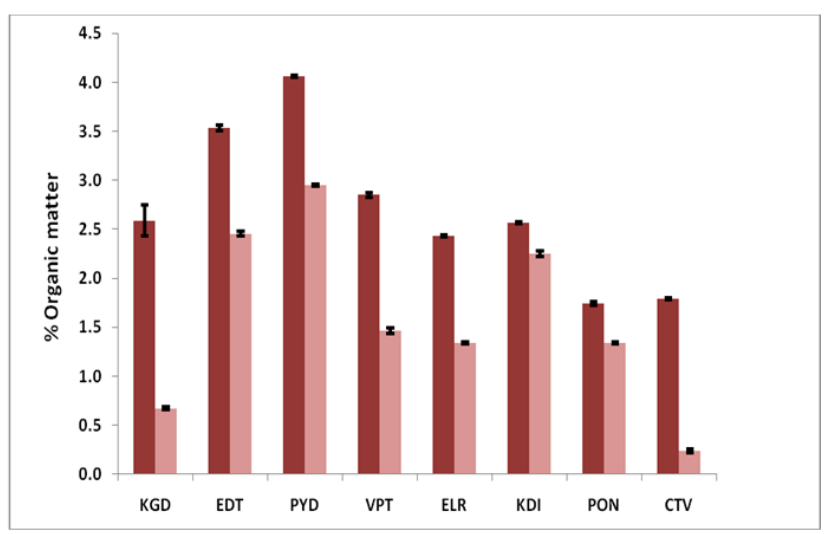

Fig. 5: Organic matter $(\%)$ of the sediments from the collection sites during monsoon and post monsoon in.

Dark red bars: Monsoon; Light red bars: Post monsoon. Values are represented as Mean $\pm \mathrm{SD}$.

KGD - Kasaragod, EDT - Edat, PYD - Pazhayangadi, VPT Valapattanam, ELR - Elathur, KDI - Kadalundi, PON - Ponnani, CTV - Chettuva

all the 8 collection sites during post monsoon compared to monsoon period. The percentage of organic matter in the mangrove sediments from all the sites studied also showed a decreasing pattern as the season shifted from monsoon to post monsoon. The decrease in the organic matter and the moisture content of the sediments as the monsoon recedes might be the reason for the reduction in the number of cultivable yeast colonies. Previous studies on the relationship between sediment physico chemical characteristics and the microbial population have shown that the microbial load in sediments is directly affected by its composition. ${ }^{16,17}$ Higher percentage of organic matter

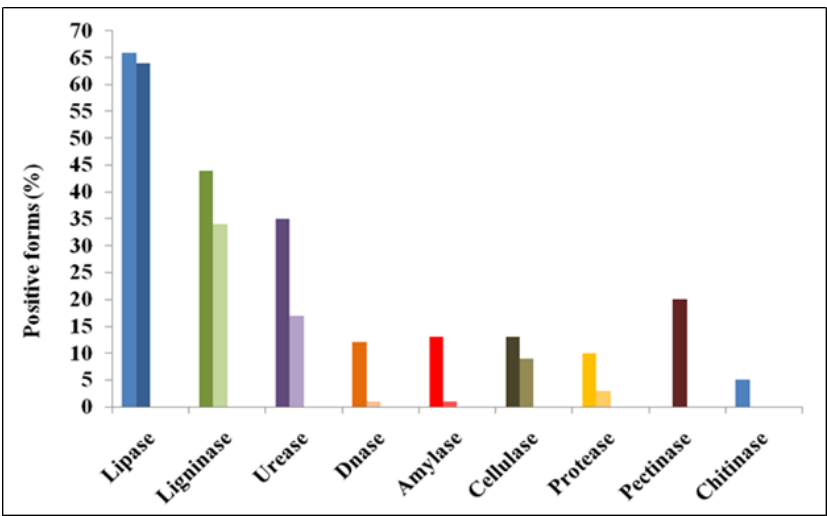

Fig. 6: Percentage of yeast isolates (Positive forms) showing various enzyme activities during two different study periods. Dark coloured bars: Monsoon; Light coloured bars: Post monsoon

and increased moisture content in the soil increases the microbial biomass significantly. ${ }^{18}$ Thus, the results from our study also substantiate the effect of organic matter, sediment texture and moisture content of the sediment on the occurrence of cultivable yeast colonies.

The number of yeast isolates showing various enzymatic activities (positive forms) was higher during post monsoon despite the reduction in number of cultivable colonies during the same period. This result leads to the fact that as the moisture content and the organic matter of the sediment decreased the number of potent isolates with hydrolytic enzyme activity increased. A study by Kutty et al. (2014) ${ }^{3}$ showed an increased hydrolytic enzyme potential in yeast strains isolated from Bay of Bengal where organic matter was recorded low. Unfavorable conditions like dehydration and decrease in the organic content of the sediment might have likely facilitated the growth of potent yeast strains over the non potent ones. Thus, the change in the pattern of hydrolytic potential of the yeast isolates would be due to changes in the atmospheric and sediment conditions that occur during seasonal fluctuations.

Majority of the yeast isolates from the mangrove sediments under the study were lipolytic and ligninolytic. This shows the presence of lipid and lignin substances and its metabolic processes in the sediments. The extracellular enzymes produced by yeasts have variety of applications in industrial processes. Besides this, they are also very important in the environment due to the property of biodegradation, where it can be used for conservation and management of the ecosystem. Microbial lipases have large number of applications in the detergent, food, flavor, pharmaceutical, agrochemical, chemical and cosmetic industries. ${ }^{19}$ Lipases are also effectively used in the bioremediation of environments contaminated with aliphatic and aromatic compounds, organic pollutants, 2, 


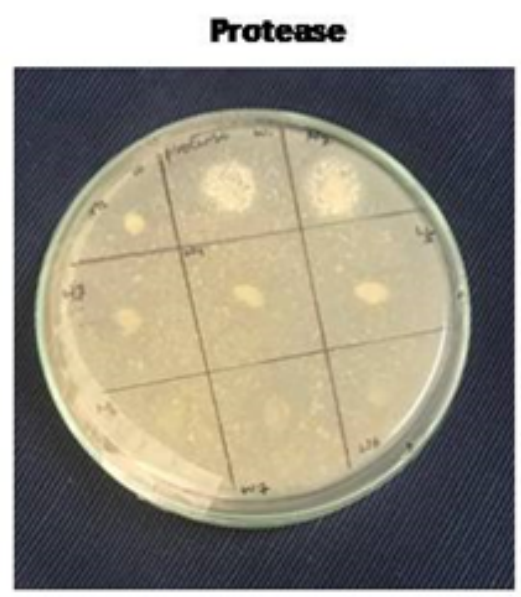

DNase

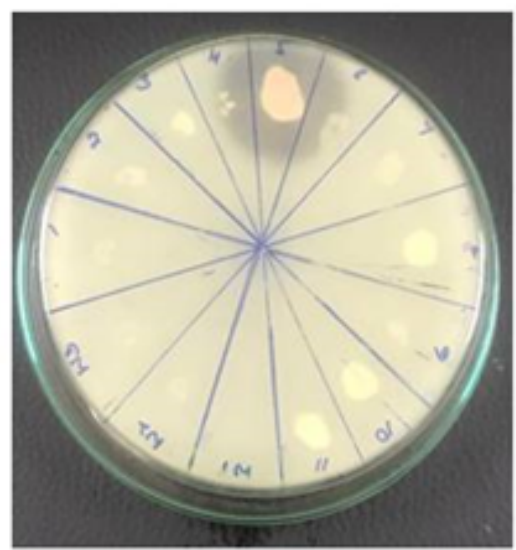

Amylase

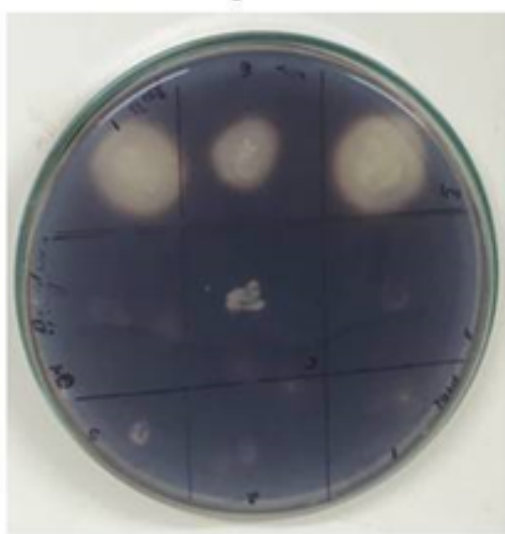

lipase

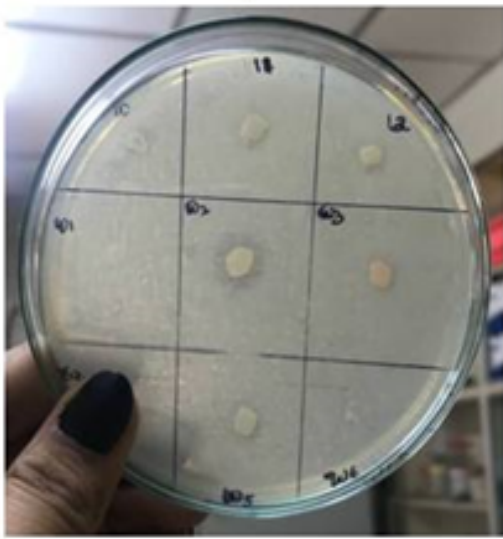

Ligninase

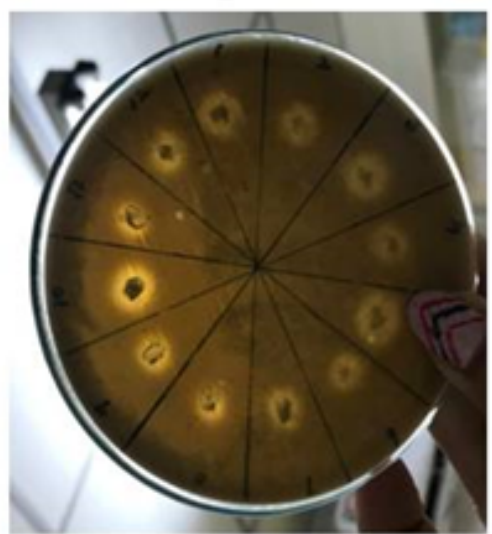

Urease

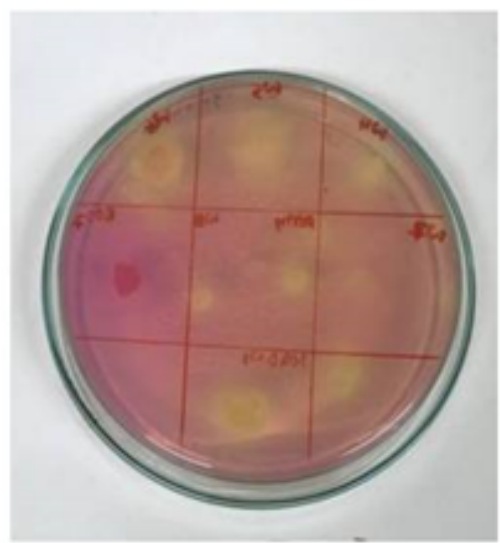

Fig. 7: Plates showing various hydrolytic enzyme activities of yeast isolates. Clearance/halozone or brown/red colour around the colonies was considered as positive

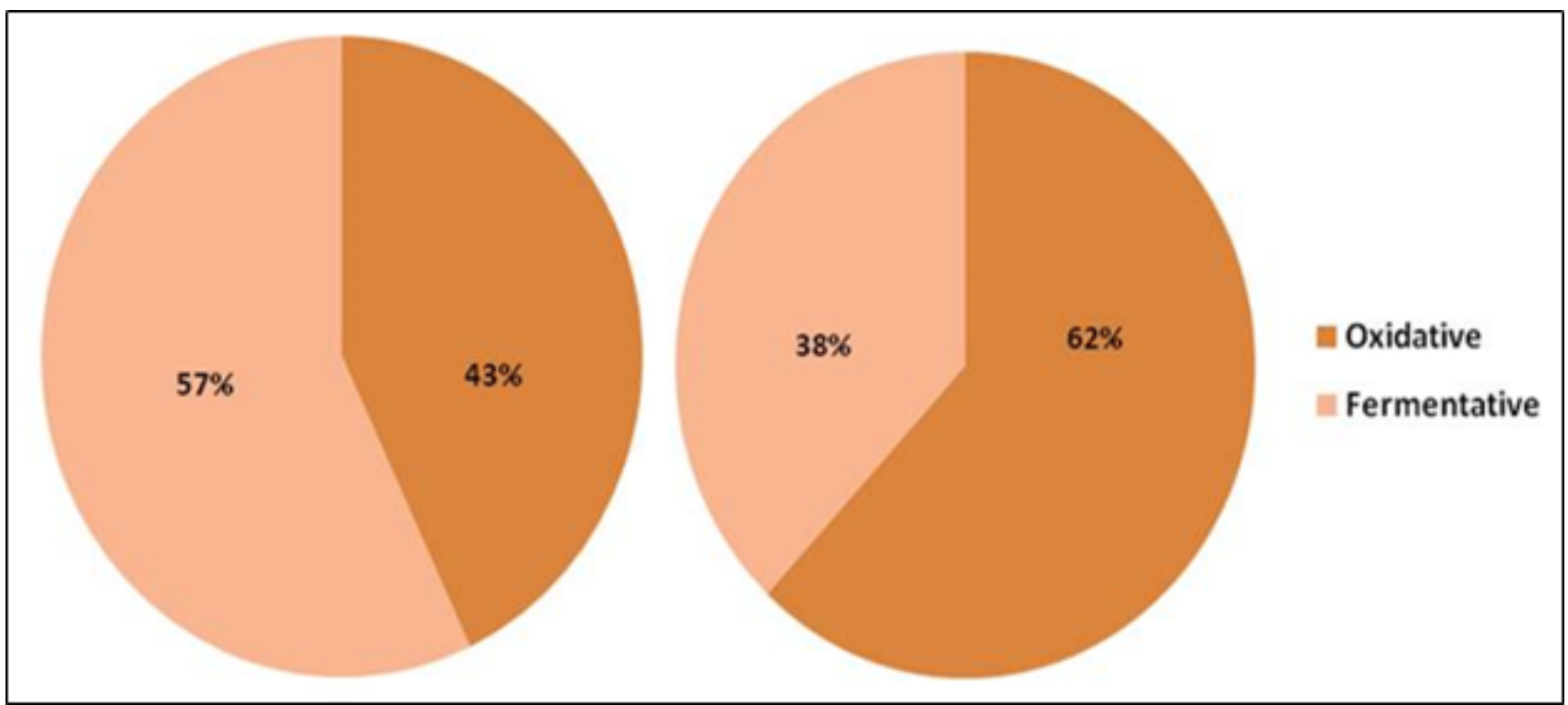

Fig. 8: Percentage of oxidative and fermentative forms during monsoon (A) and post monsoon (B) 
4, 6-trinitrotoluene, and metals. ${ }^{20}$ Yeasts with ligninolytic activity are least studied even though they have potential to degrade a range of the lignocellulosic biomass, including recalcitrant and highly toxic phenolic compounds. Ligninolytic properties have wide industrial applications, including food, textile, pulp and paper. ${ }^{21}$ Since a good number of yeasts isolated from the mangrove sediments during our study showed considerable lipase and ligninase activity, they can be further grown and optimized for the large scale production of these enzymes.

The isolates showed a shift from fermentative to oxidative forms as the season progressed from monsoon to post monsoon. It has been observed that aquatic yeasts are largely asporogenous and oxidative in nature. Studies comparing the yeast strains from polluted and non polluted waters have proved that oxidative yeasts are obtained from clean waters while fermentative forms dominated polluted waters. ${ }^{22}$ In the present study, yeast isolates from polluted mangrove sediments (eg: Valapattanam) were found to be majorly fermentative forms while those from pristine sediments (eg: Kadalundi) were predominantly oxidative forms. During monsoon, large influx of pollutants from the nearby reservoirs along with the running rain water gets trapped in the mangrove sediments. This might be the reason for the abundance of fermentative yeast forms during that period.

Since mangroves are bestowed with extreme sediment characteristics, the yeasts isolated from these sediments would also possess unique enzymatic properties differing from other ecosystems. ${ }^{23}$ This needs research attention so as to explore novel bioactive compounds which can be applied in industries and also in the management of mangrove ecosystem. The current study thus attempts to highlight the need of microbial ecology studies in unique environments like mangroves that can be effectively used for the development of strategies for the conservation of this ecosystem. The findings from our study suggest that post monsoon season of the year harbored much potent yeast isolates in mangrove sediments compared to other periods. This is mainly due to challenging environmental conditions like decreased moisture content and organic matter in the sediments they dwell. Hence, the post monsoon season can be considered as the best period to study, isolate and extract hydrolytic enzymes of yeasts from mangrove sediments. Further, the promising yeast isolates showing higher hydrolytic activities for particular enzymes will be identified and optimized to maximize their production in liquid or solid state using suitable methods for future applications.

\section{Abbreviations}

CFU/ml - Number of Colony Forming Units per Mille litre of the diluted sample; $\mathrm{Dt}$ - District.

\section{Source of Funding}

The study is been funded by Back to Lab Projects - Women Scientists Division, Kerala State Council for Science, Technology and Environment.

\section{Conflict of Interest}

None.

\section{References}

1. Mendes L, Tsai S. Variations of Bacterial Community Structure and Composition in Mangrove Sediment at Different Depths in Southeastern Brazil. Divers. 2014;6(4):827-43.

2. Holguin G, Vazquez P, Bashan Y. The role of sediment microorganisms in the productivity, conservation, and rehabilitation of mangrove ecosystems: an overview. Biol Fertil Soils. 2001;33(4):26578.

3. Kutty SN, Damodaran B, Philip R. Yeast isolates from the slope sediments of Arabian Sea and Bay of Bengal: Physiological characterization. Adv Appl Sci Res. 2014;5(5):177-87.

4. Paskevicius A, Bedoya L, Castrillón MR, Cadavid EO. Yeast diversity associated to sediments and water from two Colombian artificial lakes. Biologija. 2001;45(1):16-8.

5. Lazarus CR, Koburger JA. Identification of Yeasts From the Suwannee River Florida Estuary1. Appl Microbiol. 1974;27(6):1108-11.

6. Was BE, Dabrowski W. The seasonal variability of yeasts and yeastlike organisms in water and bottom sediment of the Szczecin Lagoon. Int J Hyg Envir Heal. 2001;203(5):451-8.

7. Hagler AN, Gabor P, Rosa C. Yeasts as Indicators of Environmental Quality. Biodiv and Ecophys Yeasts. Berlin: Springer; 2006.

8. Medeiros AO, Kohler LM, Hamdan JS, Missagia BS, Barbosa FAR, Rosa CA. Diversity and antifungal susceptibility of yeasts from tropical freshwater environments in Southeastern Brazil. Water Res. 2008;42(14):3921-9.

9. de Araujo FV, Soares CAG, Hagler AN, Mendonça-Hagler LC. Ascomycetous yeast communities of marine invertebrates in a Southeast Brazilian mangrove ecosystem. Antonie van Leeuwenhoek. 1995;68(2):91-9.

10. Soares EV, Mota M. Quantification of yeast flocculation. J Inst Brew. 1997;103(2):93-8.

11. Kutty SN, Philip R. Marine yeasts—a review. Yeast. 2008;25(7):46583.

12. Gadanho M, Sampaio J. Application of temperature gradient gel electrophoresis to the study of yeast diversity in the estuary of the Tagus river, Portugal. FEMS Yeast Res. 2004;5(3):253-61.

13. Naskar KR, Mandal RN. Ecology and Biodiversity of Indian Mangroves. New Delhi, India: Daya Publishing House; 1999.

14. Wickerham LJ. Taxonomy of yeasts. Agric Tech Bull. 1951;p. 1-19.

15. Trivedi RK, Goel PK. Chemical and biological methods for water pollution studies. Envirl publication. Karad, India; 1986.

16. Rezende LA, Assis LC, Nahas E. Carbon, nitrogen and phosphorus mineralization in two soils amended with distillery yeast. Bioresour Technol. 2004;94(2):159-67.

17. Mohammadi K, Heidari G, Khalesr S, Sohrabi Y. Soil management, microorganisms and organic matter interactions: A review. Afr J Biotech. 2011;10(84):40-9.

18. Laldinthar R, Dkhar MS. Relationship between Soil Bacterial Population and Various Physico- Chemical Properties at Two Broadleaved Forest Stands of Meghalaya Differing in Altitudes. Transcriptomics. 2015;03(02):125-32.

19. Hasan F, Shah AA, Hameed A. Industrial applications of microbial lipases. Enz Microb Technol. 2006;39(2):235-51.

20. Kotogan A, Németh B, Vagvolgyi C, Papp T, Tako M. Screening for Extracellular Lipase Enzymes with Transesterification Capacity in Mucoromycotina Strains. Food Technol Biotechnol. 2014;5(1):73-82. 
21. Saili NS, Siddiquee S, Michael C, Ling WV, González M, Kumar S. Lignocellulolytic activities among Trichoderma Isolates from Lahad Datu, Sabah and Deception Island. Antarctic J Microb Biochem Technol. 2014;6(5):295-302.

22. Hagler AN, Mendonça-Hagler LC. Yeasts from Marine and Estuarine Waters with Different Levels of Pollution in the State of Rio de Janeiro, Brazil. Appl Environ Microbiol. 1981;41(1):173-8.

23. Chi ZM, Liu TT, Chi Z, Wang ZP. Occurrence and Diversity of Yeasts in the Mangrove Ecosystems in Fujian, Guangdo.ng and Hainan Provinces of China. Indian J Microbiol. 2012;52(3):346-53.

\section{Author biography}

Sebastian Chempakassery Devasia Associate Professor

Cite this article: Pothayi V, Devasia SC. A study on the distribution and hydrolytic enzyme potential of yeasts in the mangrove sediments of Northern Kerala. Indian J Microbiol Res 2020;7(2):161-167. 